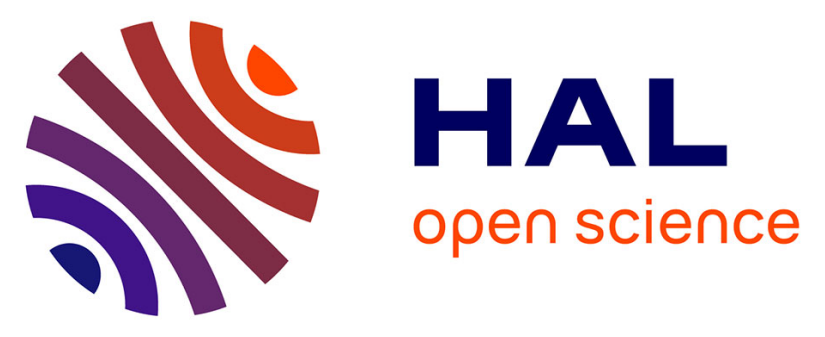

\title{
The low intestinal and hepatic toxicity of hydrolyzed fumonisin B1 correlates with its inability to alter the metabolism of sphingolipids
}

Bertrand Grenier, Ana-Paula Loureiro-Bracarense, Heidi Elisabeth Schwartz, Catherine Trumel, Anne Marie Cossalter, Gerd Schatzmayr, Martine

Kolf-Clauw, Wulf-Dieter Moll, Isabelle P. Oswald

\section{To cite this version:}

Bertrand Grenier, Ana-Paula Loureiro-Bracarense, Heidi Elisabeth Schwartz, Catherine Trumel, Anne Marie Cossalter, et al.. The low intestinal and hepatic toxicity of hydrolyzed fumonisin B1 correlates with its inability to alter the metabolism of sphingolipids. Biochemical Pharmacology, 2012, 83 (10), pp.1465-1473. 10.1016/j.bcp.2012.02.007 . hal-02648285

\section{HAL Id: hal-02648285 \\ https://hal.inrae.fr/hal-02648285}

Submitted on 7 Sep 2021

HAL is a multi-disciplinary open access archive for the deposit and dissemination of scientific research documents, whether they are published or not. The documents may come from teaching and research institutions in France or abroad, or from public or private research centers.
L'archive ouverte pluridisciplinaire HAL, est destinée au dépôt et à la diffusion de documents scientifiques de niveau recherche, publiés ou non, émanant des établissements d'enseignement et de recherche français ou étrangers, des laboratoires publics ou privés. 
The low intestinal and hepatic toxicity of hydrolyzed fumonisin $B_{1}$ correlates with its inability to alter the metabolism of sphingolipids.

Bertrand GRENIER ${ }^{1,3}$, Ana-Paula F. L. BRACARENSE ${ }^{2}$, Heidi Elisabeth SCHWARTZ ${ }^{4}$, Catherine TRUMEL ${ }^{5}$, Anne-Marie COSSALTER ${ }^{1}$, Gerd SCHATZMAYR ${ }^{3}$, Martine KOLFCLAUW $^{1,5}$, Wulf-Dieter MOLL ${ }^{3}$ and Isabelle P. OSWALD ${ }^{1}$

${ }^{1}$ INRA, UMR 1331 ToxAlim, Immuno-Myco-Toxicology team, Toulouse, France.

${ }^{2}$ Universidade Estadual de Londrina, Lab. Patologia Animal, Londrina, Brazil.

${ }^{3}$ BIOMIN Research Center, Technopark 1, Tulln, Austria.

${ }^{4}$ Christian Doppler Laboratory for Mycotoxin Metabolism, University of Natural Resources and Life Sciences, Vienna, Department IFA Tulln, Tulln, Austria.

${ }^{5}$ Université de Toulouse, Ecole Nationale Vétérinaire, Toulouse, France.

Address correspondence to

Dr Isabelle P. Oswald INRAE, UMR 1331 ToxAlim

180 chemin de Tournefeuille BP 9317331027 Toulouse Cedex 3

Phone : +33561285480 E-Mail : isabelle.oswald inrae.fr

Short running title: Toxicity of hydrolyzed Fumonisin $\mathrm{B}_{1}$

Abbreviation: $A P_{1}$, Aminopentol; b.w., body weight; CerS, Ceramide Synthase; $F B_{1} F_{2}$ $\mathrm{FB}_{3}$, Fumonisin $\mathrm{B}_{1} \mathrm{~B}_{2} \mathrm{~B}_{3}$; GGT, Gamma-Glutamyl Transferase; HE, Hematoxylin-Eosin; HFB 1 $\mathrm{HFB}_{2} \quad \mathrm{HFB}_{3}$, Hydrolyzed Fumonisin $\mathrm{B}_{1} \mathrm{~B}_{2} \mathrm{~B}_{3} ; \mathrm{HPLC}-\mathrm{FLD}$, High Performance Liquid Chromatography with Postcolumn Fluorescence Derivatization; IFN, Interferon; IL, Interleukin; IPEC-1, Intestinal Porcine Epithelial Cell line; LC-MS, Liquid ChromatographyMass Spectrometry; MHC-II, Major Histocompatibility Complex class II; NOAEL, No Observable Adverse Effect Level; OPA, Ortho-Phthalaldehyde; ppm, parts per million (or $\mathrm{mg} / \mathrm{kg}$ of feed); RPL32, Ribosomal Protein L32; Sa, Sphinganine; SEM, Standard Error of Mean; SI, Small Intestine; So, Sphingosine; TCA, Tricarballylic Acids; TNF, Tumor Necrosis Factor.

\section{ABSTRACT}

Fumonisins are mycotoxins frequently found as natural contaminants in maize, where they are produced by the plant pathogen Fusarium verticillioides. They are toxic to animals and exert their effects through mechanisms involving disruption of sphingolipid metabolism. Fumonisin $B_{1}\left(F B_{1}\right)$ is the predominant fumonisin in this family. $F B_{1}$ is converted to its hydrolyzed analogs $\mathrm{HFB}_{1}$, by alkaline cooking (nixtamalization) or through enzymatic degradation. The toxicity of $\mathrm{HFB}_{1}$ is poorly documented especially at the intestinal level. The objectives of this study were to compare the toxicity of $\mathrm{HFB}_{1}$ and $\mathrm{FB}_{1}$ and to assess the ability of these toxins to disrupt sphingolipids biosynthesis. $\mathrm{HFB}_{1}$ was obtained by a deesterification of $\mathrm{FB}_{1}$ with a carboxylesterase. Piglets, animals highly sensitive to $\mathrm{FB}_{1}$, were exposed by gavage for 2 weeks to $2.8 \mu \mathrm{mol} \mathrm{FB}_{1}$ or $\mathrm{HFB}_{1} / \mathrm{kg}$ body weight/day. $\mathrm{FB}_{1}$ induced hepatotoxicity as indicated by the lesion score, the level of several biochemical analytes and the expression of inflammatory cytokines. Similarly, FB $_{1}$ impaired the morphology of the different segments of the small intestine, reduced villi height and modified intestinal cytokine expression. By contrast, $\mathrm{HFB}_{1}$ did not trigger hepatotoxicity, did not impair intestinal morphology and slightly modified the intestinal immune response. This low toxicity of $\mathrm{HFB}_{1}$ correlates with a weak alteration of the sphinganine/sphingosine ratio in the liver and in the plasma. Taken together, these data demonstrate that $\mathrm{HFB}_{1}$ does not cause intestinal or hepatic toxicity in the sensitive pig model and only slightly disrupts sphingolipids metabolism. This finding suggests that conversion to $\mathrm{HFB}_{1}$ could be a good strategy to reduce $\mathrm{FB}_{1}$ exposure.

Keywords: fumonisin, hydrolyzed fumonisin, sphingoid bases, liver, digestive tract 


\section{INTRODUCTION}

Mycotoxins are structurally low-molecular-weight metabolites produced by fungi. As secondary metabolites they are not essential to fungi growth but may contaminate animal feed and human food at all stages of the food chain. Their worldwide occurrence is considered to be a major risk factor affecting human and animal health, and in addition leads to considerable worldwide economic losses.

Among mycotoxins, fumonisins are of major concern. These metabolites produced by Fusarium verticillioides and other fungi are common fungal contaminants of corn and some other grains [1]. Indeed, as much as $59 \%$ of corn and corn-based products are contaminated worldwide with variable amounts of fumonisin $\mathrm{B}_{1}\left(\mathrm{FB}_{1}\right)$. Fumonisin $\mathrm{B}_{2}\left(\mathrm{FB}_{2}\right)$ and $\mathrm{B}_{3}\left(\mathrm{FB}_{3}\right)$ are simultaneously produced with $\mathrm{FB}_{1}$ on grains, and the difference from $\mathrm{FB}_{1}$ is related to the absence of hydroxyl group in $\mathrm{FB}_{2}$ and $\mathrm{FB}_{3}$ on the aminopentol backbone. However, $\mathrm{FB}_{1}$ remains the most prevalent of the fumonisin subspecies, about $70-80 \%$ of the total fumonisins content [2]. Fumonisins exert complex biological effects. The toxic effects of fumonisins range from hepatotoxicity and renal toxicity to species-specific effects such as pulmonary edema in pigs and leukoencephalomalacia in horses [3, 4]. In humans, exposure to fumonisins has been linked to esophageal cancer and neural tube defects $[4,5]$. The effect on the intestine has been less investigated but villous alterations, reduced expression of immune mediators and an increase in intestinal colonization by opportunistic pathogenic bacteria in piglets have been detected $[6,7,8]$.

Fumonisins are structurally similar to sphingoid bases, and were identified as potent inhibitors of sphinganine $\mathrm{N}$-acyl transferase (ceramide synthase) [9]. Toxicity and carcinogenicity of fumonisins are related to the disruption of sphingolipid metabolism that occurs as a result of inhibition of ceramide synthase [4, 9].

Several strategies have been developed to reduce fumonisin exposure. The alkali treatment of $\mathrm{FB}_{1}$-contaminated maize, named nixtamalization, is widely used in Latin America, to produce tortillas [10]. This alkaline hydrolysis cleaves the tricarballylic acid side chains of $F B_{1}$ leading to the formation of hydrolyzed fumonisin $B_{1}\left(H F B_{1}\right)$. Conversion of $F_{1}$ to $\mathrm{HFB}_{1}$ can also be obtained by microbial degradation, through the use of fumonisin carboxylesterases, an enzyme specific of the $\mathrm{FB}_{1}$ catabolism [11, 12]. Carboxylesterases are ubiquitous enzymes, which can be found in tissues of all animals, and are responsible for detoxification of numerous exogenous compounds. However, so far it has not been demonstrated inside of animals a degradation of $\mathrm{FB}_{1}$ through these enzymes.

Toxicity of $\mathrm{HFB}_{1}$ is poorly documented. In vitro and in vivo data indicate that $\mathrm{HFB}_{1}$ has a limited ability to inhibit ceramide synthase $[13,14,15]$. Hepatic and renal lesions were reported in rats fed nixtamalized material containing $\mathrm{HFB}_{1}[16,17]$. By contrast, in mice fed purified $\mathrm{HFB}_{1}$, no hepatotoxicity or pathological changes were detected [14]. Similarly, HFB was not carcinogenic in rats [18] and did not affect fetal development through the formation of neural tube defects in either mice or rats, whether intraperitoneally or orally administered $[15,19]$. Thus, conflicting data exist on the toxicity of $\mathrm{HFB}_{1}$.

Pig is highly sensitive to $\mathrm{FB}_{1}$ and, upon short term exposure, adverse effects are observed in this animal species at lower levels than in rodents [8, 20, 21]. Pig is potentially exposed to high level of $\mathrm{FB}_{1}$. In addition pig can be regarded as the most relevant animal model for extrapolating to humans, with a digestive physiology very similar to that of human $[22,23]$.

The objectives of this study were to compare the toxicity of $\mathrm{HFB}_{1}$ and $\mathrm{FB}_{1}$ and to assess the ability of these toxins to disrupt sphingolipid biosynthesis using the sensitive pig model $[8,21] . \mathrm{HFB}_{1}$ did not induce intestinal and hepatic toxicity at a dose level that was significantly higher than the reported NOAEL for $\mathrm{FB}_{1}$ [19]. HFB ${ }_{1}$ slightly disrupted sphingolipid metabolism, although much less potently than $\mathrm{FB}_{1}$. Together, the findings indicate that, $\mathrm{HFB}_{1}$ is less toxic than $\mathrm{FB}_{1}$, and that conversion of $\mathrm{FB}_{1}$ to $\mathrm{HFB}_{1}$ could be a good strategy to reduce fumonisin exposure. 


\section{MATERIAL and METHODS}

\subsection{Animals}

Eighteen, 4-week-old weaned female piglets (Pietrain/Duroc/Large-white) weighting at the beginning of the experiment $10.96 \pm 0.23 \mathrm{Kg}$ were obtained locally in France. Animals were acclimatized for 1 week in the animal facility of the INRA ToxAlim Unit (Toulouse, France), prior to being used in experimental protocols. Six pigs were allocated to each treatment on the basis of body weight; Control group: $10.98 \pm 0.16$; FB 1 group: $10.92 \pm 0.51$; $\mathrm{HFB}_{1}$ group: $10.98 \pm 0.46$. During the 14-day experimental period, animals were given free access to water and were fed with a basal diet ad libitum, as previously described [21]. All animal experimentation procedures were carried out in accordance with the European Guidelines for the Care and Use of Animals for Research Purposes (Directive 86/609/EEC). Three of the authors have an official agreement from the French Veterinary Services for animal experimentation.

\subsection{Mycotoxins}

Lyophilised culture material of Fusarium verticillioides, containing $13.7 \mathrm{~g} / \mathrm{kg} \mathrm{FB} 1,5.2$ $\mathrm{g} / \mathrm{kg} \mathrm{FB}$, and $1.7 \mathrm{~g} / \mathrm{kg} \mathrm{FB}$, was obtained from Biopure - Romer Labs Diagnostic $\mathrm{GmbH}$, Tulln, Austria. Aliquots of $24.25 \mathrm{~g}$ culture material were resuspended in $250 \mathrm{ml} 10 \mathrm{mM}$ sodium phosphate buffer $\mathrm{pH} 7.0$, homogenised with an ultra-turrax, incubated at $22^{\circ} \mathrm{C}$ for 30 min, and centrifuged for $10 \mathrm{~min}$ at $8,000 \mathrm{rpm}$ in a Beckman JA10 rotor. This extraction was repeated twice. The supernatants from all three extractions of all aliquots were combined, the $\mathrm{pH}$ was re-adjusted to 7.0 , and this extract was separated into two equal halves in $5 \mathrm{~L}$ bottles. Fumonisin carboxylesterase FumD was prepared by fermentation of recombinant Pichia pastoris as previously described [11]. Lyophilised fermentation supernatant was dissolved in water at a concentration of $100 \mathrm{mg} / \mathrm{ml}$, and $774 \mu \mathrm{l}$ of this solution was added per liter to one of the two aliquots of extract. Both aliquots were incubated overnight at $22^{\circ} \mathrm{C}$ with shaking at $60 \mathrm{rpm}$, and both were heat-inactivated by boiling in a microwave oven for one minute in aliquots of about $650 \mathrm{ml}$. A portion of the FumD solution was heat-inactivated for $40 \mathrm{~min}$ in a boiling water bath, and the same amount of enzyme that was used for preparation of the hydrolysed fumonisin extract was added, in heat-inactivated form, to the intact fumonisin extract. Samples of both extracts from before, during, and after incubation were analysed by LC-MS using a previously described method [11] to confirm that the fumonisins were hydrolysed and intact, respectively, in the two extracts. Since more material was required, the extracts were combined with equal amounts of extracts which were prepared from the same culture material in the same way, except that water instead of $10 \mathrm{mM}$ phosphate buffer was used for extraction. The final extract of intact fumonisins was analysed by Quantas Romer Labs Diagnostic GmbH, Tulln, Austria, using a certified LC-MS method, and found to contain $530.85 \mathrm{mg} / \mathrm{l} \mathrm{FB} 1,133.30 \mathrm{mg} / \mathrm{l} \mathrm{FB}$, and $35.60 \mathrm{mg} / \mathrm{FB}_{3}$. Extracts were stored at $20^{\circ} \mathrm{C}$. For the no fumonisins control group, $5 \mathrm{mM}$ sodium phosphate containing the same concentration of heat-inactivated FumD as the two extracts was made.

\subsection{Experimental design and tissue/blood sampling}

Animals received daily by gavage the different solutions (control, $\mathrm{FB}_{1}, \mathrm{HFB}_{1}$ ) at the concentration of $2.8 \mu \mathrm{mol} \mathrm{FB}_{1} / \mathrm{kg}$ b.w/day. At weekly time intervals, blood samples were aseptically collected from the left jugular vein. Blood was collected in tubes containing sodium heparin for biochemistry, or citrate for fibrinogen measurement (Vacutainer ${ }^{\circledR}$, Becton-Dickinson, USA). Plasma samples were obtained after centrifugation of blood and stored at $-20^{\circ} \mathrm{C}$ for later analysis. Upon termination of the experiment, corresponding to 14 days of dietary exposure to treatments, immediately after electrical stunning, pigs were killed by exsanguinations, and liver and the entire gastrointestinal tract were removed. The mesentery was cut using scissors, and the small intestine (SI) was aligned on a table and measured without applying tension. The SI was divided into three parts of equal length, and $15-\mathrm{cm}$ tissue segments were collected from the middle of each part (named in the present study as Proximal SI, Mid SI and Distal SI). Subsamples of the SI segments were either fixed 
in $10 \%$ buffered formalin (Sigma, Saint-Quentin Fallavier, France) for histopathological analysis or flash-frozen in liquid nitrogen and stored at $-80^{\circ} \mathrm{C}$ until RNA extraction. Liver and mesenteric nodes were similarly prepared, and for liver an additional piece of hepatic tissue (5 to $15 \mathrm{~g}$ for each animal) was kept at $-80^{\circ} \mathrm{C}$ until sphingolipid analysis.

\subsection{Biochemistry}

Plasma concentrations of albumin, total proteins, cholesterol, triglycerides, fibrinogen and activity of gamma-glutamyl transferase were determined by a Vitros 250 analyzer (Ortho Clinical Diagnostics, Issy les Moulineaux, France) at the Veterinary School of Toulouse (France).

\subsection{Determination of sphinganine (Sa)/sphingosine (So) ratios}

Assessment of sphingolipid metabolism, by measurement of the content of sphingoid bases in plasma and liver samples, was carried out according to Yoo et al. [24] with some modifications. In short, $200 \mu \mathrm{l}$ aliquots of plasma samples were spiked with $\mathrm{C}_{17}$-sphingosine and $\mathrm{C}_{20}$-sphinganine (Avanti Polar Lipids, Alabama, USA) as internal standards, $400 \mu \mathrm{l}$ of chloroform (p.a., Merck, Darmstadt, Germany) and $1.3 \mathrm{ml}$ of methanolic potassium hydroxide solution ( $0.154 \mathrm{M}$ reagents from Merck) were added and samples were shaken at $37^{\circ} \mathrm{C}$ for 1 h. After further addition of $1.2 \mathrm{ml}$ of chloroform, the chloroform phase was washed three times with alkaline water (samples vortexed and centrifuged at $2500 \mathrm{rpm}$ for 5-8 min between each washing) and subsequently evaporated to dryness. The residues were derivatized using OPA reagent (final volume $300 \mu \mathrm{l}$ ) according to Riley et al. [25] and the resulting solutions were measured by HPLC-FLD. For analysis of liver samples, aliquots of frozen liver samples were homogenized on ice in the fourfold volume of cold phosphate buffer. Then, $100 \mu \mathrm{l}$ aliquots of the homogenates were diluted with $100 \mu \mathrm{l}$ of water and worked up and analyzed in the same way as the plasma samples.

For HPLC-FLD analysis, $25 \mu \mathrm{l}$ of derivatized standards or sample extracts were injected into the HPLC-system (Agilent 1100 series, Waldbronn, Germany) and separated on a C6 phenyl column (50 x $2 \mathrm{~mm}, 5 \mu \mathrm{m}$, Phenomenex, Aschaffenburg, Germany) equipped with a pre-column of the same stationary phase at $0.5 \mathrm{ml} / \mathrm{min}$ using gradient elution. Mobile phase $A$ and $B$ consisted of methanol (gradient grade for LC, Merck)/water/glacial acetic acid (p.a., Merck) (A: 60:39.9:0.1, v/v/v; B: 90:9.9:0.1, v/v/v). The following gradient was used: 0 min: 0\% B, 4.5 min: 84\% B, 6.8 min: $90 \%$, 9 min: $90 \%$ B, 9.5 min: $100 \%$ B, $13.9 \min : 100 \%$ B, $14 \mathrm{~min}: 0 \% \mathrm{~B}, 16 \mathrm{~min}: 0 \% \mathrm{~B}$. Analytes were detected fluorimetrically (excitation at $335 \mathrm{~nm}$, emission at $440 \mathrm{~nm}$ ). Concentrations of Sa and So were determined on the basis of external calibration functions and the Sa/So ratio was calculated for each animal in the biological samples.

\subsection{Determination of tissue lesions and villous morphometry}

The tissue pieces were dehydrated through graded alcohols and embedded in paraffin wax. Sections of $3 \mu \mathrm{m}$ were stained with hematoxylin-eosin (HE, Sigma) for histopathological evaluation. Microscopic observations in liver and in SI were quantified as already described $[21,26]$ with minor modifications (Table 1). A lesion score per animal was established by taking into account the importance degree of the lesion (severity factor) and its extent (intensity or observed frequency; scored from 0 to 3). Morphometry was evaluated in the different segments of intestine, by measuring the villi height randomly on thirty villi using a MOTIC Image Plus $2.0 \mathrm{ML} \circledast$ image analysis system, as already described [26]. To evaluate lesions and morphometry in these tissues, the slides were observed in a blind way by the same pathologist, and irrespective of the experimental groups.

\subsection{Expression of $m R N A$ encoding for cytokines by real-time $P C R$}

Tissue RNA was processed in lysing matrix D tubes (MP Biomedicals, Illkirch, France) containing guanidine-thiocyanate acid phenol (Extract-All囚, Eurobio, les Ulis, France) for use with the FastPrep-24 (MP Biomedicals, Illkirch, France). Concentrations, integrity and quality of RNA were determined spectrophotometrically (O.D.260) using 
Nanodrop ND1000 (Labtech International, Paris, France). The steps and conditions of reverse transcription and real-time PCR were performed as previously described [21, 26]. The sequences of the primers used in PCR are detailed in Table 2. Primers were purchased from Invitrogen (Cergy Pontoise, France). Amplification efficiency and initial fluorescence were determined by DART-PCR method. Then, the values obtained were normalized by both house-keeping genes $\beta 2$-microglobulin and ribosomal protein L32 (RPL32). Finally, gene expression was expressed relative to the control group.

\subsection{Statistical analysis}

Following the Fisher test on equality of variances, one way ANOVA using Statview software 5.0 (SAS Institute, Cary, NC, USA) was used to analyze the differences between the different treatment groups of animals at each time point. $P$ values of 0.05 were considered significant.

\section{RESULTS}

\subsection{Comparative effects of $F B_{1}$ and $H F B_{1}$ on the liver}

Ingestion of $\mathrm{FB}_{1}$ has been demonstrated to be hepatotoxic [3, 4]. It was thus of interest to compare the effect of ingestion of $\mathrm{FB}_{1}$ and $\mathrm{HFB}_{1}$ on the liver.

\subsubsection{Histopathology}

The lesions observed in the liver were mild to moderate for all the animals. The main lesions observed in piglets treated with $\mathrm{FB}_{1}$ were a nuclear vacuolization of hepatocytes, and megalocytosis. One piglet also presented signs of necrosis. As indicated by the lesion score, animals fed $\mathrm{FB}_{1}$ displayed significant liver lesions when compared to control animal $\left(p<0.001\right.$, Figure 1). By contrast, the lesion score observed in animals fed $\mathrm{HFB}_{1}$ was similar to the one observed in control animals, indicating that $\mathrm{HFB}_{1}$ did not induce severe liver damages.

\subsubsection{Biochemical analytes}

Next, the effect of $\mathrm{FB}_{1}$ and $\mathrm{HFB}_{1}$ on plasmatic biochemical analytes, as biomarkers of liver lesion and inflammation, was compared. A time related increase in albumin, total protein concentrations, cholesterol and triglycerides, fibrinogen and gamma-glutamyl transferase (GGT) were observed in animals treated with $\mathrm{FB}_{1}$ for 7 and 14 days (Table 3). Conversely, ingestion of $\mathrm{HFB}_{1}$ for 7 or 14 days did not induce any change in the plasmatic biochemical analytes (Table 3 ) when compared with the values measured for control animals.

\subsubsection{Cytokines expression}

Liver also produces cytokines, with pro- or anti-inflammatory properties. The comparative effect of the ingestion of $\mathrm{FB}_{1}$ and $\mathrm{HFB}_{1}$ on the expression of cytokine mRNA in the liver was analyzed and described in Table 4. In FB 1 -treated animals, an increased liver expression of IL- $1 \beta$ and IL- 8 mRNA was observed when compared to control animals $(+55 \%$ and $+82 \%$ respectively). The ingestion of the toxin also significantly decreased the liver expression of IL-6, IL-10, IL-18 and IFN- $\gamma(-28 \%,-51 \%,-40 \%$ and $-31 \%$ respectively, when compared to control).

By contrast, 14 days of exposure to $\mathrm{HFB}_{1}$, had only a minor effect on the liver expression of cytokines. Among the 6 cytokines measured, $\mathrm{HFB}_{1}$ significantly modulated only the expression of IL-6 (-29\% when compared to control group).

Taken together, these data indicate that ingestion of $\mathrm{HFB}_{1}$ induced minimal liver toxicity as measured by the liver lesion (Figure 1), blood biochemistry (Table 3 ) and liver cytokine expression (Table 4). 


\subsection{Comparative effects of $F B_{1}$ and $H F B_{1}$ on the small intestine}

The digestive tract is the first compartment exposed to mycotoxins and several studies have demonstrated that the intestine is a target for $\mathrm{FB}_{1}$ [27]. The effect of $\mathrm{FB}_{1}$ and $\mathrm{HFB}_{1}$ were compared along the small intestine (SI).

\subsubsection{Histopathology}

As already observed in the liver, the intestinal lesions were mild to moderate. Ingestion of $\mathrm{FB}_{1}$ induced lymphatic vessel dilation and interstitial edema in the proximal-SI, as well as lymphatic vessel dilation, villi atrophy and fusion, in both mid- and distal-SI. In all sections of the small intestine, the lesion score observed in $\mathrm{FB}_{1}$-treated animals was significantly higher than the one observed in control animals $(p<0.05, p<0.001, p<0.05$ in proximal, mid and distal $\mathrm{SI}$, respectively). Ingestion of $\mathrm{HFB}_{1}$ did not elicit significant lesions in the small intestine, and the lesion scores were not statistically different from the ones observed in control animals (Figure 2).

The morphology of the intestine was also evaluated by measuring the villi height. As reported in Table $5, \mathrm{FB}_{1}$ significantly decreased the height of villi in the small intestine $(-20 \%$ and $-31 \%$ mid and distal SI, respectively). By contrast, ingestion of HFB $\mathrm{HF}_{1}$ had a moderate, non-significant effect on this parameter (Table 5).

\subsubsection{Cytokines expression}

The digestive tract is also an immune organ and the ingestion of $\mathrm{FB}_{1}$ is known to modulate the intestinal expression of cytokine $[6,28]$. In the current study, we compared the effect of $\mathrm{FB}_{1}$ and $\mathrm{HFB}_{1}$ on the expression of cytokines in the different parts of the small intestine and mesenteric lymph nodes.

As shown in Figure 3, ingestion of $\mathrm{FB}_{1}$ decreased significantly the expression of mRNA encoding for IL-1 $\beta$, IL-10, IL-2 and IFN- $\gamma$ in the proximal SI $(-59 \%,-43 \%,-41 \%,-46 \%$, respectively), IL-1 $\beta$, IL-6, IL-2 and IFN- $\gamma$ in the mid SI $(-38 \%,-33 \%,-38 \%,-46 \%$, respectively), IL-1 $\beta$ and IL-8 in the distal SI (-56\%, $-42 \%$ respectively), and the levels of mRNA encoding for IL-1 $\beta$, IL-8, IL-6, TNF- $\alpha$, IL-2, IFN- $\gamma$ and IL-12p40 in mesenteric nodes ($51 \%,-59 \%,-14 \%,-27 \%,-24 \%,-29 \%$ and $-45 \%$, respectively)

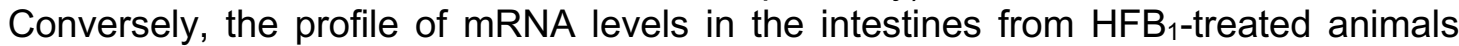
was only slightly altered when compared to control animals. We only observed a significant alteration of IL-12p40 in the mid- and distal SI ( $+91 \%$ and $+54 \%$, respectively), IFN $-\gamma$ in the distal SI (+61\%) as well as an alteration of TNF- $\alpha$ and IL-6 expression in the mesenteric lymph nodes (-26\% and $-18 \%$ respectively).

Taken together, these data indicate that when compared with ingestion of $\mathrm{FB}_{1}$, ingestion of $\mathrm{HFB}_{1}$ was found to induce minimal intestinal toxicity as measured by the histopathology (Figure 2), morphology (Table 5) and cytokine expression (Figure 3).

\subsection{Comparative effect of $F B_{1}$ and $H F B_{1}$ on sphingolipid metabolism}

FB1 disrupts sphingolipid metabolism by inhibiting ceramide synthases, leading to an increased sphinganine (Sa)/sphingosine (So) ratio in tissues and body fluids [4]. Concentrations of $\mathrm{Sa}$ and So were measured in plasma and liver samples from piglets belonging to the three different experimental groups and the Sa/So ratios were calculated. As expected, ingestion of $\mathrm{FB}_{1}$ induced an accumulation of $\mathrm{Sa}$ and to a lesser extent of So both in plasma and liver of piglets. As shown in Figure 4, the Sa/So ratios of animals treated with $\mathrm{FB}_{1}$ was 8 to 10 fold higher in plasma and 28 fold higher in liver, when compared with control animals.

By contrast, ingestion of $\mathrm{HFB}_{1}$ did not affect the sphingolipid metabolism in the plasma samples. In the liver, the Sa/So ratio was two-fold higher in animals treated with $\mathrm{HFB}_{1}$ when compared with the control animals. 


\section{DISCUSSION}

The aim of the current study was to compare the in vivo toxicity of $F B_{1}$ and its fully hydrolyzed form, HFB 1 (also named aminopentol $\mathrm{AP}_{1}$ ). HFB $\mathrm{HF}_{1}$ is produced during nixtamalization, a traditional corn treatment used in Mexico, Central America, as well as in the United States, to make masa and tortillas [10]. This alkaline hydrolysis process, using calcium hydroxide and heat, removes the tricarballylic acid side chains from $\mathrm{FB}_{1}$. Processing of contaminated foods/feeds by fumonisin carboxylesterase and/or microorganisms expressing this enzyme may also lead to the formation of $\mathrm{HFB}_{1}$ [11]. The data presented in this paper clearly show that hydrolysis of $\mathrm{FB}_{1}$ strongly reduces its toxicity, both in the liver and the gastrointestinal tract.

In the present study, piglets were exposed to $2.8 \mu$ mol $\mathrm{FB}_{1}$ or $\mathrm{HFB}_{1} / \mathrm{kg}$ b.w./day for 14 days. This $\mathrm{FB}_{1}$ concentration allowed to induce toxicity, and thus to compare at equimolar concentration the $\mathrm{HFB}_{1}$ effects. Based on averaged feed consumption for pigs of this age, this dose corresponds to feed contaminated with a concentration of $37-44 \mathrm{mg}$ of $\mathrm{FB}_{1} / \mathrm{kg}$.

Over the 14 days exposure period, no effect on animal growth was observed (data not shown). This is in agreement with earlier studies where no effect on body weight gain was reported in pigs fed $47 \mathrm{mg} \mathrm{FB} / \mathrm{kg}$ feed [29]. Signs of hepatotoxicity were observed upon ingestion of $\mathrm{FB}_{1}$, and are in accordance with previous reports [3, 4]. In the present study, biochemical markers of hepatic and renal lesions showed moderate increases, except GGT showing higher increase. Although this toxin is able to target different tissues or cells according to species, $\mathrm{FB}_{1}$ commonly acts on the liver of both laboratory and farms animals, and affects structural integrity and functions. Microscopic changes observed in the present experiment were already described in the literature, and included a disorganization of hepatic cords, hepatocellular vacuolation, megalocytosis, apoptosis, necrosis and cell proliferation [3, 4]. Similarly, biochemical changes were reported in pigs after $\mathrm{FB}_{1}$ ingestion [29]. Analysis of the cytokines network upon exposure to this mycotoxin is less documented. Nevertheless, an increase of mRNA encoding for the pro-inflammatory mediators IL-1 $\beta$ and IL-8 has already been observed in the liver or the lung of treated animals [30, 31]. Levels of IL-6 and IL-10, cytokines with anti-inflammatory properties [32, 33], were greatly reduced in liver and could thereby confirm the inflammatory state in piglets exposed to $\mathrm{FB}_{1}$ [34].

By contrast, hepatotoxicity was not observed in $\mathrm{HFB}_{1}$-treated piglets, as measured by the liver lesion, blood biochemistry and liver cytokine expression. Indeed, no microscopic lesion (megalocytosis, vacuolar degeneration) was noticed in those animals. Similarly, biochemical analytes linked with protein and lipid metabolism were not altered by the ingestion of $\mathrm{HFB}_{1}$. The plasmatic concentrations of GGT and fibrinogen were also unaffected following $\mathrm{HFB}_{1}$ exposure. These results confirm previous observations including the absence of lesions and the unmodified values of biochemical analytes in animals exposed to purified $\mathrm{HFB}_{1}[4,15,35]$. However, it should be mentioned that in vitro, the hydrolysis products of $\mathrm{FB}_{1}$ and $\mathrm{FB}_{2}$, especially $\mathrm{HFB}_{2}$ exhibited a higher cytotoxic activity on primary rat hepatocytes than their respective parent molecules [18]. In the present experiment, the liver expression of cytokines was slightly modulated in animals exposed to $\mathrm{HFB}_{1}$, but to a lesser extent than in those from tht $\mathrm{FB}_{1}$ group. To the best of our knowledge this is the first report on the effect of $\mathrm{HFB}_{1}$ on cytokines in liver.

In this study, we also compared the intestinal toxicity of $\mathrm{FB}_{1}$ and $\mathrm{HFB}_{1}$. The gastrointestinal tract is a primary site of mycotoxins exposure, and following ingestion of contaminated food or feed, intestinal epithelial cells could be exposed to a high concentration of toxicants, potentially affecting intestinal functions [27]. $\mathrm{FB}_{1}$ was proven to affect the intestine as shown by the in situ inhibition of ceramide synthase [36, 37]. This inhibition, could explain some adverse effects reported, such as alteration of the proliferation and the barrier function of intestinal cells [38]. In the present study, we observed that the intestine of animals exposed to this mycotoxin displayed mild to moderate tissular lesions including villi atrophy and fusion. Occurrence of these lesions was high in the intestine of animals exposed to $\mathrm{FB}_{1}$, especially in the second part of the small intestine. These findings are in agreement with the villous fusion and atrophy observed in the intestine of pigs treated with similar doses of $\mathrm{FB}_{1}(30 \mathrm{ppm})$ [7] and in the intestine of chicks fed with $61-546 \mathrm{ppm} \mathrm{FB}_{1}$ [39]. Effects of 
$\mathrm{HFB}_{1}$ on the intestine are poorly documented. Most of the data concern the effect of this toxin on intestinal cell lines to assess its effect on cell viability, $\mathrm{HFB}_{1}$ acylation or sphingoid bases content [35, 40,41]. In the current study, we observed that ingestion of $\mathrm{HFB}_{1}$ does not alter the intestinal integrity, as assessed by the villi morphometry and the lesion scores in different intestinal segments.

The intestine is also an immune site where immunoregulatory mechanisms simultaneously defend against pathogens and preserve tissue homeostasis to avoid immune-mediated pathology in response to environmental challenges [42]. Few data are available with regard to the effects of $\mathrm{FB}_{1}$ on the intestinal immunity, and even lesser on cytokines production. $\mathrm{FB}_{1}$ decreases the expression and the synthesis of IL-8 in the porcine epithelial intestinal cell line, IPEC-1 and in the ileum of animals exposed to the toxin [6]. The $\mathrm{FB}_{1}$-induced IL-8 decrease may lead to a reduced recruitment of inflammatory cells in the intestine during infection and may participate in the observed increased susceptibility of exposed piglets to intestinal infections $[8,43]$. $\mathrm{FB}_{1}$ exposure also leads to a reduced intestinal expression of IL-12p40, an impaired function of intestinal antigen presenting cells, with decreased upregulation of major histocompatibility complex class II molecule (MHC-II) and reduced $\mathrm{T}$ cell stimulatory capacity upon stimulation [28]. In the present study, a decreased expression of most of the cytokines was observed in the different part of the intestinal compartments following $\mathrm{FB}_{1}$ ingestion. Indeed, an important decrease of the IL-1 $\beta$, IL-2, IFN- $\gamma$ and to a lesser extent IL-8 mRNAs was observed in the upper intestinal tract and in the gut-associated lymphoid tissue.

By contrast, the intestinal profile of cytokines after exposure to $\mathrm{HFB}_{1}$ revealed minimal changes when compared with non-exposed animals. These changes included a slight upregulation of the expression of some cytokines in the mid and distal parts of the $\mathrm{SI}$, and a slight downregulation of TNF- $\alpha$ and IL- 6 mRNAs in the mesenteric nodes. In comparison to the changes induced upon FB1 exposure, these HFB1 effects are very weak. This suggests that animals consuming $\mathrm{HFB}_{1}$ would be able to drive a correct immune response and to defend efficiently against potential invaders. To our knowledge, this is the first study investigating the effect of $\mathrm{HFB}_{1}$ on the intestinal morphology and the immune response.

$\mathrm{FB}_{1}$ inhibits ceramide synthase, leading to an accumulation of sphinganine and to a lesser extent of sphingosine. The Sa/So ratio is a sensitive biomarker of FB1 toxicity and indicates the degree of sphingolipid metabolism disruption [9, 25]. This elevation in sphinganine, a highly bioactive compound, initiates a cascade of cellular alterations that are thought to be largely responsible for the toxicity of $\mathrm{FB}_{1}$. To inhibit ceramide synthase, the aminopentol backbone of $\mathrm{FB}_{1}$ competes for binding of the sphingoid base substrate, whereas the tricarballylic acids (TCA) side chains interfere with binding of the fatty acid acyl-CoA [40, 44]. Removal of the TCA diminishes the potency of ceramide synthase inhibition, and therefore the accumulation of sphingoid bases. In the present work, we observed that ingestion of $\mathrm{HFB}_{1}$ didn't block ceramide synthase, which is in line with previous reports, that the TCA moieties are required for maximal inhibition of the enzyme [13, 14, 15, 18, 45]. Nevertheless, it should be mentioned that $\mathrm{HFB}_{1}$ is not only an inhibitor but also a substrate for acylation by ceramide synthase [35, 40]. The absence of TCA allows $\mathrm{HFB}_{1}$ to be acylated, and acylation was observed in the presence of palmitoyl-CoA leading to the formation of $\mathrm{N}$ palmitoyl-AP ${ }_{1}$. This latter compound is highly cytotoxic for HT29 cells, and a potent inhibitor of ceramide synthase [40]. Acylation was also evaluated in rats, and while formation of $\mathrm{N}$ acyl-AP ${ }_{1}$ occurs and produces metabolites with fatty acids of various chain lengths, no toxicity was observed [35]. We cannot exclude that acylation occurred in our experiment, however neither increase in sphinganine concentrations nor toxicity were detected. Nonetheless, this aspect warrants further investigations, considering that there are multiple isoforms of ceramide synthase (CerS) showing different tissular expression and difference in fatty acyl-CoA selectivity. Results may also vary depending on animal species.

This paper demonstrates that ingestion of $\mathrm{HFB}_{1}$ results in strongly reduced toxicity compared to ingestion of $\mathrm{FB}_{1}$. Absence of reproductive and hepatic toxicity of $\mathrm{HFB}_{1}$ has already been described in rats and in mice exposed to the toxin during feeding trials or by intra-peritoneal injection [14, 15, 19]. The present study expands this knowledge by adding 
that $\mathrm{HFB}_{1}$ does not induce toxic effect in the intestine (lesion, inflammatory reaction) or inflammation in the liver. Previous studies which suggested toxicity of $\mathrm{HFB}_{1}[16,17,46]$ were performed with nixtamalized culture material and it has been proposed that the toxic effects were mediated by residual, partially hydrolyzed or "hidden" $\mathrm{FB}_{1}$ (matrix bound forms not detected by HPLC) remaining in the nixtamalized preparations [15, 35, 47, 48, 49]. The HFB 1 used in this study was obtained by enzymatic treatment of Fusarium verticillioides culture material with the fumonisin carboxylesterase FumD [11], and complete hydrolysis, i.e., absence of partially hydrolyzed fumonisins, was confirmed by LC-MS. Our results indicate that, $\mathrm{HFB}_{1}$ is less toxic than $\mathrm{FB}_{1}$. Thus, microbial degradation of $\mathrm{FB}_{1}$, with carboxylesterase, could be a good strategy to reduce fumonisin exposure.

\section{ACKNOWLEDGMENTS}

B. Grenier was supported by a doctoral fellowship (CIFRE 065/2007), jointly financed by the BIOMIN Holding GmbH, ANRT (Association Nationale de la Recherche Technique) and INRA (Institut National de la Recherche Agronomique). This study was supported in part by a CAPES/COFECUB Grant (No. 593/08) and a CNDT Grant (No. 472048/2008-2). We thank G. Jaunecker for preparing the fungal culture material, A. Frank for help with preparing the extracts, I. Schöner and A. Seeböck for assistance with the sphingolipid analyses, P. Pinton and J. Laffitte for technical assistance during the animal experiments, and C. A. Moll for help with the English.

\section{REFERENCES}

[1] MARASAS WFO. Discovery and occurrence of the fumonisins: A historical perspective. Environ Health Perspect. 2001; 109: 239-243.

[2] BINDER EM, TAN LM, CHIN LJ, HANDL J, ICHARD J. Worldwide occurrence of mycotoxins in commodities, feeds and feed ingredients. Anim. Feed Sci. Technol. 2007; 137: 265-282.

[3] HASCHEK WM, GUMPRECHT LA, SMITH G, TUMBLESON ME, CONSTABLE PD. Fumonisin toxicosis in swine: An overview of porcine pulmonary edema and current perspectives. Environ. Health Perspect. 2001; 109: 251-257.

[4] VOSS KA, SMITH GW, HASCHEK WM. Fumonisins: Toxicokinetics, mechanism of action and toxicity. Anim. Feed Sci. Technol. 2007; 137: 299-325.

[5] GELDERBLOM W, MARASAS W. Controversies in fumonisin mycotoxicology and risk assessment. Hum. Exp. Toxicol. 2012; in press

[6] BOUHET S, LE DORZE E, PERES S, FAIRBROTHER JM, OSWALD IP. Mycotoxin fumonisin B-1 selectively down-regulates the basal IL-8 expression in pig intestine: in vivo and in vitro studies. Food Chem Toxicol. 2006; 44: 1768-1773.

[7] PIVA A, CASADEI G, PAGLIUCA G, CABASSI E, GALVANO F, SOLFRIZZO M, RILEY RT, DIAZ DE. Activated carbon does not prevent the toxicity of culture material containing fumonisin B-1 when fed to weanling piglets. J Anim Sci. 2005; 83: 1939 1947.

[8] OSWALD IP, DESAUTELS C, LAFFITTE J, FOURNOUT S, PERES SY, ODIN M, LE BARS, P, LE BARS J, FAIRBROTHER JM. Mycotoxin fumonisin B-1 increases intestinal colonization by pathogenic Escherichia coli in pigs. Appl Environ Microbiol. 2003; 69: 5870-5874.

[9] SORIANO JM, GONZALEZ L, CATALA AI. Mechanism of action of sphingolipids and their metabolites in the toxicity of fumonisin B1. Prog Lipid Res. 2005; 44: 345-356.

[10] DOMBRINK-KURTZMAN MA, DVORAK TJ, BARRON ME, ROONEY LW. Effect of nixtamalization (alkaline cooking) on fumonisin-contaminated corn for production of masa and tortillas. J Agri Food Chem. 2000; 48: 5781-5786.

[11] HEINL S, HARTINGER D, THAMHESL M, VEKIRU E, KRSKA R, SCHATZMAYR G, MOLL, WD, GRABHERR R. Degradation of fumonisin B-1 by the consecutive action of two bacterial enzymes. J Biotechnol. 2010; 145: 120-129. 
[12] HARTINGER D, MOLL WD. Fumonisin elimination and prospects for detoxification by enzymatic transformation. World Mycotoxin J. 2011; 4: 271-283.

[13] VAN DER WESTHUIZEN L, SHEPHARD GS, SNYMAN SD, ABEL S, SWANEVELDER S, GELDERBLOM WCA. Inhibition of sphingolipid biosynthesis in rat primary hepatocyte cultures by Fumonisin, B-1 and other structurally related compounds. Food Chem Toxicol. 1998; 36: 497-503.

[14] HOWARD PC, COUCH LH, PATTON RE, EPPLEY RM, DOERGE DR, CHURCHWELL MI, MARQUES MM, OKERBERG CV. Comparison of the toxicity of several fumonisin derivatives in a 28-day feeding study with female B6C3F(1) mice. Toxicol. Appl. Pharmacol. 2002; 185: 153-165.

[15] VOSS KA, RILEY RT, SNOOK ME, GELINEAU-VAN WAES J. Reproductive and Sphingolipid Metabolic Effects of Fumonisin B-1 and its Alkaline Hydrolysis Product in LM/Bc Mice: Hydrolyzed Fumonisin B-1 Did Not Cause Neural Tube Defects. Toxicol Sci. 2009; 112: 459-467.

[16] VOSS KA, BACON CW, MEREDITH FI, NORRED WP. Comparative subchronic toxicity studies of nixtamalized and water-extracted Fusarium moniliforme culture material. Food Chem Toxicol. 1996; 34: 623-32.

[17] VOSS KA, RILEY RT, BACON CW, MEREDITH FI, NORRED WP. Toxicity and sphinganine levels are correlated in rats fed fumonisin B-1 (FB1) or hydrolyzed FB1. Environ Toxicol Pharmacol. 1998; 5: 101-104.

[18] GELDERBLOM WCA, CAWOOD ME, SNYMAN SD, VLEGGAAR R, MARASAS WFO. Structure-Activity-Relationships of Fumonisins in Short-Term Carcinogenesis and Cytotoxicity Assays. Food Chem Toxicol. 1993; 31: 407-414.

[19] COLLINS TFX, SPRANDO RL, BLACK TN, OLEJNIK N, EPPLEY RM, SHACKELFORD ME, HOWARD PC, RORIE JI, BRYANT M, RUGGLES DI. Effects of aminopentol on in utero development in rats. Food Chem Toxicol. 2006; 44: 161-169.

[20] EFSA. Opinion of the Scientific Panel on Contaminants in Food Chain on a request from the Commission related to fumonisins as undesirable substances in animal feed. EFSA J, 2005 235: 1-32.

[21] GRENIER B, LOUREIRO-BRACARENSE AP, LUCIOLI J, PACHECO GD, COSSALTER, AM, MOLL WD, SCHATZMAYR G, OSWALD IP. Individual and combined effects of subclinical doses of deoxynivalenol and fumonisins in piglets. Mol Nutr Food Res. 2011; 55: 761-771.

[22] ROTHKOTTER HJ, SOWA E, PABST R. The pig as a model of developmental immunology. Hum. Exp. Toxicol. 2002; 21: 533-536.

[23] GUILLOTEAU P, ZABIELSKI R, HAMMON HM, METGES CC. Nutritional programming of gastrointestinal tract development. Is the pig a good model for man? Nutr Res Rev. 2010; 23: 4-22.

[24] YOO HS, NORRED WP, RILEY RT. A rapid method for quantifying free sphingoid bases and complex sphingolipids in microgram amounts of cells following exposure to fumonisin B1. Toxicol in vitro. 1996; 10: 77-84.

[25] RILEY RT, WANG E, MERRILL AHJr. Liquid chromatographic determination of sphinganine and sphingosine: Use of the free sphinganine-to-sphingosine ratio as a biomarker for consumption of fumonisins. J AOAC Int. 1994; 77: 533-540.

[26] BRACARENSE APFL, LUCIOLI J, GRENIER B, PACHECO GD, MOLL WD, SCHATZMAYR G, OSWALD IP. Chronic ingestion of deoxynivalenol and fumonisin, alone or in interaction, induces morphological and immunological changes in the intestine of piglets. Br J Nutr. 2012; in press.

[27] BOUHET S, OSWALD IP. The intestine as a possible target for fumonisin toxicity. Mol Nutr Food Res, 2007; 51: 925-31

[28] DEVRIENDT B, GALLOIS M, VERDONCK F, WACHE Y, BIMCZOK D, OSWALD IP, GODDEERIS BM, COX E. The food contaminant fumonisin B-1 reduces the maturation of porcine CD11R1(+) intestinal antigen presenting cells and antigen-specific immune responses, leading to a prolonged intestinal ETEC infection. Vet Res. 2009; $40: 40$ 
[29] HARVEY RB, EDRINGTON TS, KUBENA LF, ELISSALDE MH, CASPER HH, ROTTINGHAUS GE, TURK JR. Effects of dietary fumonisin B-1-containing culture material, deoxynivalenol-contaminated wheat, or their combination on growing barrows. Am J Vet Res. 1996; 57: 1790-1794.

[30] BHANDRI N, BROWN CC, SHARMA RP. Fumonisin B-1-induced localized activation of cytokine network in mouse liver. Food Chem Toxicol. 2002; 40: 1483-1491.

[31] HALLOY DJ, GUSTIN PG, BOUHET S, OSWALD IP. Oral exposure to culture material extract containing fumonisins predisposes swine to the development of pneumonitis caused by Pasteurella multocida. Toxicology, 2005; 213: 34-44.

[32] DE VRIES JE. Immunosuppressive and Anti-inflammatory Properties of Interleukin 10. Ann Med. 1995; 27: 537-541

[33] XING Z, GAULDIE J, COX G, BAUMANN H, JORDANA M, LEI XF, ACHONG MK. IL-6 is an antiinflammatory cytokine required for controlling local or systemic acute inflammatory responses. J Clin Invest. 1998; 101: 311-320

[34] MARIN DE, TARANU I, PASCALE F, LIONIDE A, BURLACU R, BAILLY JD, OSWALD IP. Sex-related differences in the immune response of weanling piglets exposed to low doses of fumonisin extract. Br J Nutr. 2006; 95: 1185-1192.

[35] SEIFERLEIN M, HUMPF HU, VOSS KA, SULLARDS MC, ALLEGOOD JC, WANG E, MERRILL AH. Hydrolyzed fumonisins HFB1 and HFB2 are acylated in vitro and in vivo by ceramide synthase to form cytotoxic N-acyl-metabolites. Mol Nutr Food Res. 2007; 51: $1120-1130$.

[36] ENONGENE EN, SHARMA RP, BHANDARI N, VOSS KA, RILEY RT. Disruption of sphingolipid metabolism in small intestines, liver and kidney of mice dosed subcutaneously with fumonisin B-1. Food Chem Toxicol. 2000; 38: 793-799.

[37] LOISEAU N, DEBRAUWER L, SAMBOU T, BOUHET S, MILLER, JD, MARTIN PG, VIADERE JL, PINTON, P, PUEL O, PINEAU T, TULLIEZ J, GALTIER P, OSWALD IP. Fumonisin B-1 exposure and its selective effect on porcine jejunal segment: Sphingolipids, glycolipids and trans-epithelial passage disturbance. Biochem Pharmacol. 2007; 74: 144-152.

[38] BOUHET S, HOURCADE E, LOISEAU N, FIKRY A, MARTINEZ S, ROSELLI M, GALTIER P, MENGHERI E, OSWALD IP. The mycotoxin fumonisin B-1 alters the proliferation and the barrier function of porcine intestinal epithelial cells. Toxicol Sci. 2004; 77: 165-171.

[39] JAVED T, BUNTE RM, DOMBRINK-KURTZMAN MA, RICHARD JL, BENNETT GA, COTE LM, BUCK WB. Comparative pathologic changes in broiler chicks on feed amended with Fusarium proliferatum culture material or purified fumonisin B-1 and moniliformin. Mycopathologia, 2005; 159: 553-564.

[40] HUMPF HU, SCHMELZ EM, MEREDITH FI, VESPER H, VALES TR, WANG E, MENALDINO DS, LIOTTA DC, MERRILL AH. Acylation of naturally occurring and synthetic 1-deoxysphinganines by ceramide synthase - Formation of N-palmitoylaminopentol produces a toxic metabolite of hydrolyzed fumonisin, AP1, and a new category of ceramide synthase inhibitor. J Biol Chem. 1998; 273: 19060-19064.

[41] SCHMELZ EM, DOMBRINK-KURTZMAN MA, ROBERTS PC, KOZUTSUMI Y, KAWASAKI T, MERRILL AH. Induction of apoptosis by fumonisin B-1 in HT29 cells is mediated by the accumulation of endogenous free sphingoid bases. Toxicol Appl Pharmacol. 1998; 148: 252-260.

[42] RAMIRO-PUIG E, PEREZ-CANO FJ, CASTELLOTE C, FRANCH A, CASTELL M. The bowel: A key component of the immune system. Rev Esp Enferm Dig. 2008; 100: 2934.

[43] OSWALD IP, COMERA C. Immunotoxicity of mycotoxins. Rev. Med. Vet. 1998; 149: 585-590.

[44] DESAI K, SULLARDS MC, ALLEGOOD J, WANG E, SCHMELZ EM, HARTL M, HUMPF HU, LIOTTA DC, PENG Q, MERRILL AH. Fumonisins and fumonisin analogs as inhibitors of ceramide synthase and inducers of apoptosis. Biochem Biophys Acta. 2002; 1585: 188-192. 
[45] FLYNN TJ, STACK ME, TROY AL, CHIRTEL SJ. Assessment of the embryotoxic potential of the total hydrolysis product of fumonisin B-1 using cultured organogenesisstaged rat embryos. Food Chem Toxicol. 1997; 35: 1135-1141.

[46] HENDRICH S, MILLER KA, WILSON TM, MURPHY PA. Toxicity of FusariumProliferatum-Fermented Nixtamalized Corn-Based Diets Fed to Rats - Effect of Nutritional-Status. J Agri Food Chem. 1993; 41: 1649-1654.

[47] KIM EK, SCOTT PM, LAU BPY. Hidden fumonisin in corn flakes. Food Addit Contam. 2003; 20: 161-169.

[48] BURNS TD, SNOOK ME, RILEY RT, VOSS KA. Fumonisin concentrations and in vivo toxicity of nixtamalized Fusarium verticillioides culture material: Evidence for fumonisinmatrix interactions. Food Chem Toxicol. 2008; 46: 2841-2848.

[49] PARK JW, SCOTT PM, LAU BPY, LEWIS DA. Analysis of heat-processed corn foods for fumonisins and bound fumonisins. Food Addit Contam. 2004; 21: 1168-1178.

[50] PINTON P, BRAICU C, NOUGAYREDE JP, LAFFITTE J, TARANU I, OSWALD IP. Deoxynivalenol Impairs Porcine Intestinal Barrier Function and Decreases the Protein Expression of Claudin-4 through a Mitogen-Activated Protein Kinase-Dependent Mechanism. J Nutr. 2010; 140: 1956-1962.

[51] ROYAEE AR, HUSMANN RJ, DAWSON HD, CALZADA-NOVA G, SCHNITZLEIN WM, ZUCKERMANN FA, LUNNEY JK. Deciphering the involvement of innate immune factors in the development of the host response to PRRSV vaccination. Vet Immunol Immunopathol. 2004; 102: 199-216

[52] MEISSONNIER GM, PINTON P, LAFFITTE J, COSSALTER AM, GONG, YY, WILD, C. P., BERTIN G, GALTIER P, OSWALD IP. Immunotoxicity of aflatoxin B1: Impairment of the cell-mediated response to vaccine antigen and modulation of cytokine expression. Toxicol Appl Pharmacol. 2008; 231: 142-149

[53] MEURENS F, BERRI M, AURAY G, MELO S, LEVAST B, VIRLOGEUX-PAYANT I, CHEVALEYRE C, GERDTS V, SALMON H. Early immune response following Salmonella enterica subspecies enterica serovar Typhimurium infection in porcine jejunal gut loops. Vet Res. 2009; 40: 5 
Table 1: Establishment of a lesion score - endpoints used to evaluate histological lesions in liver and in the small intestine

Notes: The

\begin{tabular}{|l|l|c|}
\hline Tissue & Type of lesions (severity factor) & $\begin{array}{l}\text { Maximal } \\
\text { score }\end{array}$ \\
\hline LIVER & $\begin{array}{l}\text { Disorganization of hepatic cords (1) } \\
\text { Hepatic cell vacuolization (1) } \\
\text { Inflammatory infiltrate (1) } \\
\text { Megalocytosis (2) } \\
\text { Necrosis (2) }\end{array}$ & 21 \\
\hline SMALL & $\begin{array}{l}\text { Lymphatic vessels dilation (1) } \\
\text { Interstitial edema (2) } \\
\text { INTESTINE } \\
\text { Villi atrophy (2) } \\
\text { Villi fusion (2) }\end{array}$ & 21 \\
\hline
\end{tabular}

score for each lesion was obtained by multiplying the severity factor by the extent of the lesion. The organ score was then obtained by calculating the sum of each lesion score. Severity factor (or degree of severity), 1=mild lesions, 2=moderate lesions; the extent of each lesion (intensity or observed frequency) was evaluated and scored as $0=$ no lesion, $1=$ low extent, $2=$ =intermediate extent, $3=$ large extent.

Table 2: Nucleotide sequences of primers for real-time PCR

\begin{tabular}{|c|c|c|c|c|c|}
\hline \multirow{2}{*}{$\begin{array}{c}\text { Gene } \\
\text { RPL32 }\end{array}$} & \multicolumn{2}{|c|}{ Primer Concentration and Sequence } & \multirow{2}{*}{$\begin{array}{c}\text { Amplicon } \\
\text { Size } \\
106\end{array}$} & \multirow{2}{*}{$\begin{array}{c}\text { Genbank No } \\
\text { NM_001001 } \\
636\end{array}$} & \multirow{2}{*}{$\begin{array}{c}\text { References } \\
\text { [49] }\end{array}$} \\
\hline & $\begin{array}{l}\mathrm{F}(300 \mathrm{nM}) \\
\mathrm{R}(300 \mathrm{nM})\end{array}$ & $\begin{array}{l}\text { TGCTCTCAGACCCCTTGTGAAG } \\
\text { TTTCCGCCAGTTCCGCTTAA }\end{array}$ & & & \\
\hline $\begin{array}{c}\beta 2- \\
\text { microglobulin }\end{array}$ & $\begin{array}{l}F(900 \mathrm{nM}) \\
\mathrm{R}(300 \mathrm{nM})\end{array}$ & $\begin{array}{l}\text { TTCTACCTTCTGGTCCACACTGA } \\
\text { TCATCCAACCCAGATGCA }\end{array}$ & 162 & NM_213978 & [28] \\
\hline IL-12p40 & $\begin{array}{l}F(300 \mathrm{nM}) \\
R(900 \mathrm{nM})\end{array}$ & $\begin{array}{l}\text { GGTTTCAGACCCGACGAACTCT } \\
\text { CATATGGCCACAATGGGAGATG }\end{array}$ & 112 & NM_214013 & [28] \\
\hline IL-8 & $\begin{array}{l}F(300 \mathrm{nM}) \\
R(900 \mathrm{nM})\end{array}$ & $\begin{array}{l}\text { GCTCTCTGTGAGGCTGCAGTTC } \\
\text { AAGGTGTGGAATGCGTATTTATGC }\end{array}$ & 79 & NM_213867 & [21] \\
\hline IL-1 $\beta$ & $\begin{array}{l}\mathrm{F}(300 \mathrm{nM}) \\
\mathrm{R}(300 \mathrm{nM})\end{array}$ & $\begin{array}{l}\text { GAGCTGAAGGCTCTCCACCTC } \\
\text { ATCGCTGTCATCTCCTTGCAC }\end{array}$ & 87 & $\begin{array}{l}\text { NM_001005 } \\
149\end{array}$ & [28] \\
\hline IL-6 & $\begin{array}{l}F(300 n M) \\
R(300 n M)\end{array}$ & $\begin{array}{l}\text { GGCAAAAGGGAAAGAATCCAG } \\
\text { CGTTCTGTGACTGCAGCTTATCC }\end{array}$ & 87 & NM_214399 & [21] \\
\hline $\mathrm{IFN}-\gamma$ & $\begin{array}{l}\mathrm{F}(300 \mathrm{nM}) \\
\mathrm{R}(300 \mathrm{nM})\end{array}$ & $\begin{array}{l}\text { TGGTAGCTCTGGGAAACTGAATG } \\
\text { GGCTTTGCGCTGGATCTG }\end{array}$ & 79 & NM_213948 & [51] \\
\hline TNF- $\alpha$ & $\begin{array}{l}\mathrm{F}(300 \mathrm{nM}) \\
\mathrm{R}(300 \mathrm{nM})\end{array}$ & $\begin{array}{l}\text { ACTGCACTTCGAGGTTATCGG } \\
\text { GGCGACGGGCTTATCTGA }\end{array}$ & 118 & NM_214022 & [52] \\
\hline IL-2 & $\begin{array}{l}F(300 \mathrm{nM}) \\
\mathrm{R}(300 \mathrm{nM})\end{array}$ & $\begin{array}{l}\text { GCCATTGCTGCTGGATTTAC } \\
\text { CCCTCCAGAGCTTTGAGTTC }\end{array}$ & 159 & AY294018 & [53] \\
\hline IL-10 & $\begin{array}{l}F(300 n M) \\
R(300 n M)\end{array}$ & $\begin{array}{l}\text { GGCCCAGTGAAGAGTTTCTTTC } \\
\text { CAACAAGTCGCCCATCTGGT }\end{array}$ & 51 & NM_214041 & [26] \\
\hline
\end{tabular}




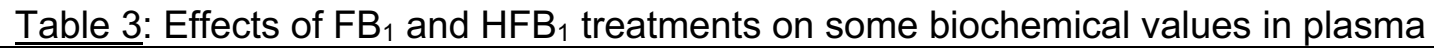

\begin{tabular}{|c|c|c|c|c|}
\hline \multirow{2}{*}{\multicolumn{2}{|c|}{ BIOCHEMICAL PARAMETERS }} & \multicolumn{3}{|c|}{ ANIMAL TREATMENTS } \\
\hline & & \multirow{2}{*}{$\begin{array}{l}\text { CONTROL } \\
26.2 \pm 0.8^{\mathrm{a}} \\
26.5 \pm 1.1^{\mathrm{a}}\end{array}$} & \multirow{2}{*}{$\begin{array}{c}\mathrm{FB}_{1} \\
31.3 \pm 0.7^{\mathrm{b}} \\
31.6 \pm 1.0^{\mathrm{b}}\end{array}$} & \multirow{2}{*}{$\begin{array}{c}\mathrm{HFB}_{1} \\
26.1 \pm 0.9^{\mathrm{a}} \\
25.1 \pm 0.7^{\mathrm{a}}\end{array}$} \\
\hline Albumin $(g / L)$ & $\begin{array}{l}\text { Day } 7 \\
\text { Day } 14\end{array}$ & & & \\
\hline Total proteins (g/L) & $\begin{array}{l}\text { Day } 7 \\
\text { Day } 14\end{array}$ & $\begin{array}{l}49.7 \pm 0.8^{a} \\
50.4 \pm 0.7^{a}\end{array}$ & $\begin{array}{l}58.7 \pm 1.4^{\mathrm{b}} \\
61.4 \pm 1.2^{\mathrm{b}}\end{array}$ & $\begin{array}{l}49.9 \pm 1.2^{\mathrm{a}} \\
50.7 \pm 0.6^{\mathrm{a}}\end{array}$ \\
\hline Triglycerides (mmol/L) & $\begin{array}{l}\text { Day } 7 \\
\text { Day } 14\end{array}$ & $\begin{array}{l}0.89 \pm 0.12^{a} \\
0.82 \pm 0.17^{a}\end{array}$ & $\begin{array}{l}1.19 \pm 0.16^{a} \\
1.34 \pm 0.14^{b}\end{array}$ & $\begin{array}{l}0.76 \pm 0.11^{a} \\
0.82 \pm 0.09^{a}\end{array}$ \\
\hline Cholesterol (mmol/L) & $\begin{array}{l}\text { Day } 7 \\
\text { Day } 14\end{array}$ & $\begin{array}{l}2.70 \pm 0.22^{a} \\
2.63 \pm 0.26^{a}\end{array}$ & $\begin{array}{l}3.78 \pm 0.21^{b} \\
4.44 \pm 0.30^{b}\end{array}$ & $\begin{array}{l}2.16 \pm 0.34^{a} \\
2.12 \pm 0.25^{a}\end{array}$ \\
\hline Fibrinogen (g/L) & $\begin{array}{l}\text { Day } 7 \\
\text { Day } 14\end{array}$ & $\begin{array}{l}2.16 \pm 0.13^{a} \\
1.68 \pm 0.05^{a}\end{array}$ & $\begin{array}{l}2.91 \pm 0.21^{b} \\
2.96 \pm 0.12^{b}\end{array}$ & $\begin{array}{l}1.89 \pm 0.27^{a} \\
1.72 \pm 0.05^{a}\end{array}$ \\
\hline GGT (U/L) & $\begin{array}{l}\text { Day } 7 \\
\text { Day } 14\end{array}$ & $\begin{array}{l}46.0 \pm 2.4^{\mathrm{a}} \\
51.2 \pm 1.4^{\mathrm{a}}\end{array}$ & $\begin{aligned} 71.2 & \pm 6.2^{\mathrm{b}} \\
146.2 & \pm 32.3^{\mathrm{b}}\end{aligned}$ & $\begin{array}{r}53.2 \pm 5.3^{\mathrm{a}, \mathrm{b}} \\
71.2 \pm 12.8^{\mathrm{a}, \mathrm{b}}\end{array}$ \\
\hline
\end{tabular}

Notes : GGT: $\gamma$-glutamyl transferase. Results are expressed as mean \pm SEM of five animals. Means in a row without a common letter differ $(P<0.05)$

Table 4: Effect of a 14-days exposure to $\mathrm{FB}_{1}$ and $\mathrm{HFB}_{1}$ on the mRNAs level of hepatic cytokines

\begin{tabular}{lccc}
\hline \multirow{2}{*}{ CYTOKINES } & \multicolumn{3}{c}{ ANIMAL TREATMENTS } \\
\cline { 2 - 4 } & CONTROL & FB $_{1}$ & HFB $_{1}$ \\
\hline IL-1 $\beta$ & $1.00 \pm 0.10^{\mathrm{a}}$ & $1.55 \pm 0.20^{\mathrm{b}}$ & $1.27 \pm 0.21^{\mathrm{a}, \mathrm{b}}$ \\
IL-8 & $1.00 \pm 0.09^{\mathrm{a}}$ & $1.82 \pm 0.55^{\mathrm{a}}$ & $1.26 \pm 0.10^{\mathrm{a}}$ \\
$\mathrm{IL}-6$ & $1.00 \pm 0.08^{\mathrm{a}}$ & $0.72 \pm 0.08^{\mathrm{b}}$ & $0.71 \pm 0.07^{\mathrm{b}}$ \\
$\mathrm{IL}-10$ & $1.00 \pm 0.15^{\mathrm{a}}$ & $0.49 \pm 0.06^{\mathrm{b}}$ & $0.98 \pm 0.08^{\mathrm{a}}$ \\
IFN- $\gamma$ & $1.00 \pm 0.11^{\mathrm{a}}$ & $0.69 \pm 0.04^{\mathrm{b}}$ & $1.00 \pm 0.25^{\mathrm{a}, \mathrm{b}}$ \\
IL-18 & $1.00 \pm 0.01^{\mathrm{a}}$ & $0.59 \pm 0.06^{\mathrm{b}}$ & $0.86 \pm 0.05^{\mathrm{a}}$ \\
\hline
\end{tabular}

Notes: Results are expressed in arbitrary units relative to the control group. Results are mean \pm SEM of 5 animals. Means in a row without a common letter differ $(P<0.05)$

Table 5: Effect of 14-days exposure to $\mathrm{FB}_{1}$ and $\mathrm{HFB}_{1}$ on the villi morphometry in the small intestine

\begin{tabular}{lccc}
\hline Small intestine & \multicolumn{3}{c}{ ANIMAL TREATMENTS } \\
\cline { 2 - 4 } segment & CONTROL & FB $_{1}$ & HFB $_{1}$ \\
\hline Proximal SI & $300 \pm 16^{\mathrm{a}}$ & $259 \pm 17^{\mathrm{a}}$ & $255 \pm 19^{\mathrm{a}}$ \\
Mid SI & $321 \pm 13^{\mathrm{a}}$ & $259 \pm 21^{\mathrm{b}}$ & $297 \pm 10^{\mathrm{a}, \mathrm{b}}$ \\
Distal SI & $265 \pm 13^{\mathrm{a}}$ & $182 \pm 13^{\mathrm{b}}$ & $241 \pm 7^{\mathrm{a}}$ \\
\hline
\end{tabular}

Notes: Results are villi height in $\mu \mathrm{m}$, they are expressed as mean \pm SEM for 5 animals. Means in a row without a common letter differ $(P<0.05)$ 


\section{FIGURES}
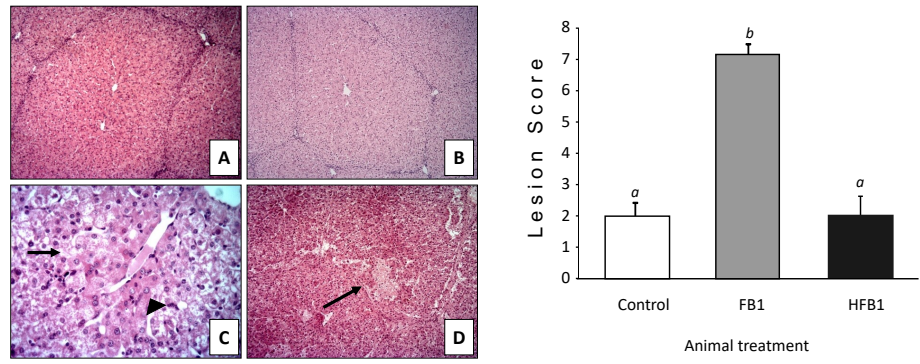

Figure 1. Effects of $\mathrm{FB}_{1}$ and $\mathrm{HFB}_{1}$ treatments at day 14 on the liver. Pigs were orally exposed to $\mathrm{FB}_{1}(\square), \mathrm{HFB}_{1}(\square)$ or were kept as control animals $(\square)$. Liver of $(A)$ a control pig, (B) a $\mathrm{HFB}_{1}$ treated-pig and (C), (D) an FB1 treated-pig. (A), (B) normal liver architecture, HE. 10x. (C) hepatocyte vacuolization (arrow) and megalocytosis (arrowhead), HE. 40x. (D) focal necrosis (arrow). HE. 10x. Lesion scores were established after histological examination according to the severity and the extent of the lesions. Values are mean \pm SEM of 5 animals. Graphic bars without a common letter differ $(P<0.05)$.
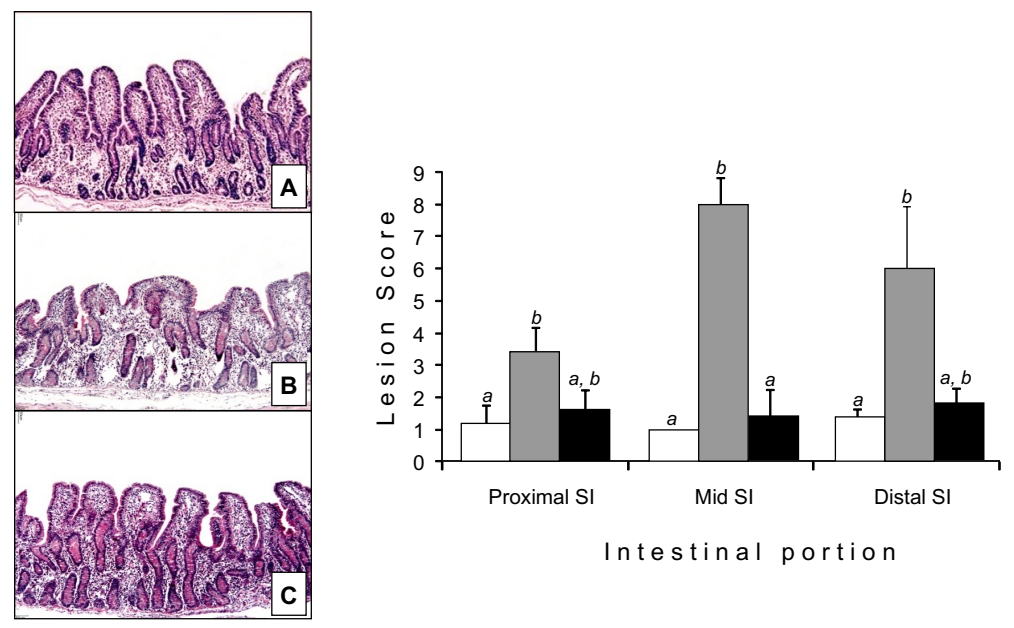

Figure 2. Effects of $\mathrm{FB}_{1}$ and $\mathrm{HFB}_{1}$ treatments at day 14 on the small intestine (SI). Pigs were orally exposed to $\mathrm{FB}_{1}(\square), \mathrm{HFB}_{1}(\boldsymbol{\square})$ or were kept as control animals $(\square)$. Mid SI of $(A)$ control animals - continuous epithelium with normal villi, (B) $\mathrm{FB}_{1}$-treated animals - discontinuous epithelium with villi flattening and fusion, and (C) $\mathrm{HFB}_{1}$-treated animals - weak villi flattening. HE. 10x. Lesion scores were established after histological examination according to the severity and the extent of the lesions. Values are mean \pm SEM of 5 animals. Graphic bars without a common letter differ $(P<0.05)$. 


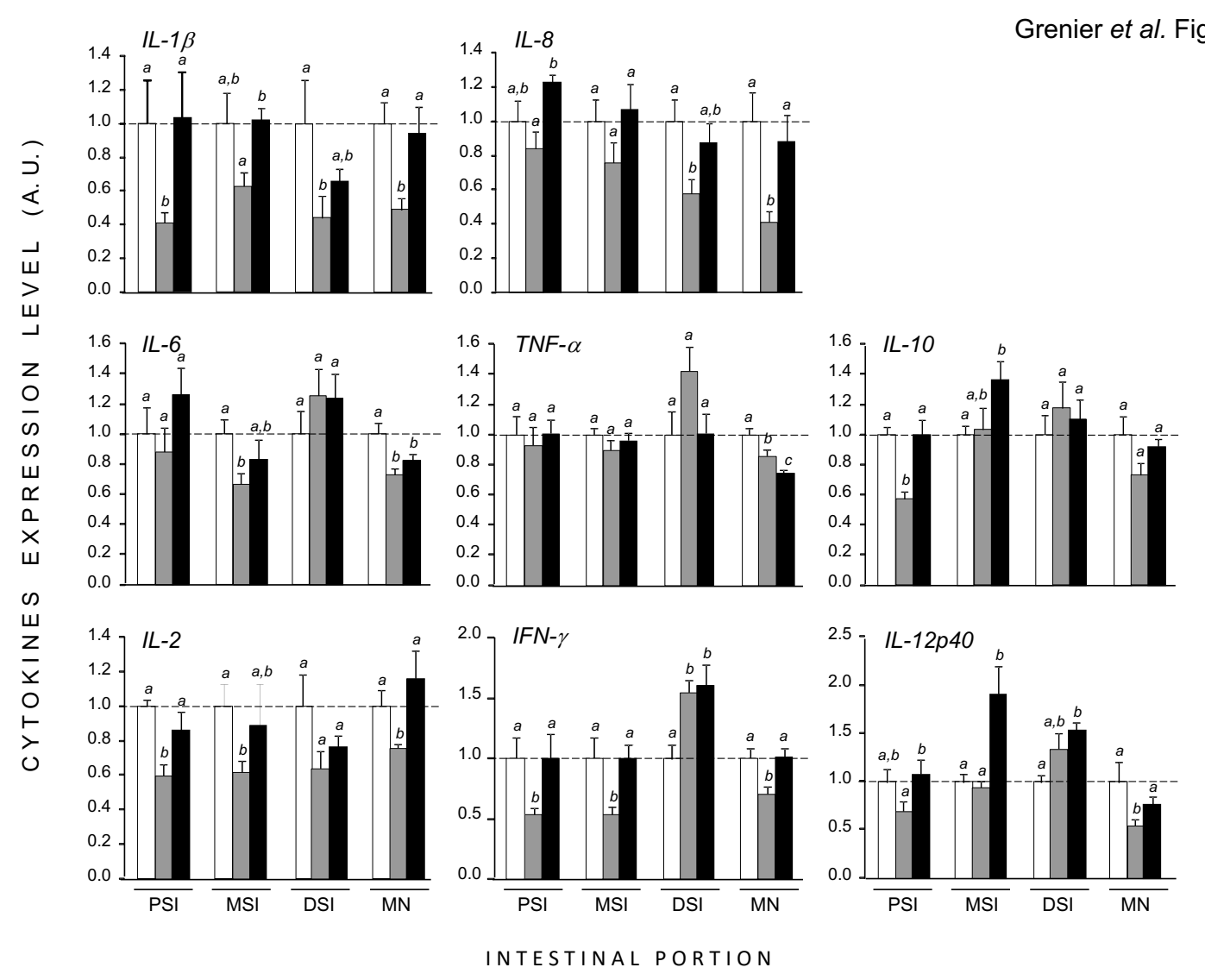

Figure 3. Effects of $\mathrm{FB}_{1}$ and $\mathrm{HFB}_{1}$ treatments at day 14 on the mRNA levels encoding cytokines in the intestine. Pigs were orally exposed to $\mathrm{FB}_{1}(\square), \mathrm{HFB}_{1}(\boldsymbol{\square})$ or were kept as control animals $(\square)$. Patterns of cytokine mRNA expression were assessed in the proximal, mid- and distal small intestine (PSI, MSI, DSI) as well as in the mesenteric nodes (MN). Quantification of the relative cytokine mRNA level for each sample is expressed in arbitrary units (A.U.). Values are mean \pm SEM of 5 animals. Graphic bars without a common letter differ $(P<0.05)$.

Grenier et al. Figure 4

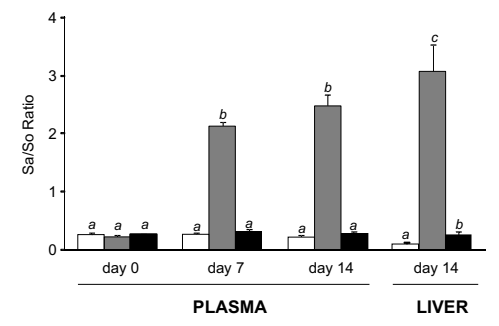

Figure 4. Effects of $\mathrm{FB}_{1}$ and $\mathrm{HFB}_{1}$ treatments on the sphinganine to sphingosine (Sa/So) ratio in plasma and liver samples. Pigs were orally exposed to $\mathrm{FB}_{1}(\square), \mathrm{HFB}_{1}(\boldsymbol{\square})$ or were kept as control animals $(\square)$. The Sa/So ratio was determined at days 0,7 and 14 in plasma samples, and at day 14 on liver samples. Values are mean \pm SEM of 6 animals. Graphic bars without a common letter differ $(P<0.05)$. 